\title{
Innovative leaching of cobalt and lithium from spent lithium-ion batteries and simultaneous dechlorination of polyvinyl chloride in subcritical water
}

\author{
Kang Liu, Fu-Shen Zhang* \\ Department of Solid Waste Treatment and Recycling, Research Center for Eco-Environmental Sciences, Chinese Academy of Sciences, 18 Shuangqing Road, \\ Beijing 100085, China
}

\section{H I G H L I G H T S}

- A co-treatment process for recovery of Co and Li and simultaneous detoxification of PVC in subcritical water was proposed.

- PVC was used as a hydrochloric acid source.

- More than $95 \%$ Co and nearly $98 \%$ Li were leached under the optimum conditions.

- Neither corrosive acid nor reducing agent was used.

- The co-treatment process has technical, economic and environmental benefits over the traditional recovery processes.

\section{A R T I C L E I N F O}

\section{Article history:}

Received 29 January 2016

Received in revised form 22 April 2016

Accepted 28 April 2016

Available online 6 May 2016

\section{Keywords:}

Spent lithium-ion battery

Dechlorination

Polyvinyl chloride

Metal leaching

Subcritical water

\begin{abstract}
A B S T R A C T
In this work, an effective and environmentally friendly process for the recovery of cobalt (Co) and lithium (Li) from spent lithium-ion batteries (LIBs) and simultaneously detoxification of polyvinyl chloride (PVC) in subcritical water was developed. Lithium cobalt oxide $\left(\mathrm{LiCOO}_{2}\right)$ power from spent LIBs and PVC were co-treated by subcritical water oxidation, in which PVC served as a hydrochloric acid source to promote metal leaching. The dechlorination of PVC and metal leaching was achieved simultaneously under subcritical water oxidation. More than $95 \% \mathrm{Co}$ and nearly $98 \% \mathrm{Li}$ were recovered under the optimum conditions: temperature $350{ }^{\circ} \mathrm{C}, \mathrm{PVC} / \mathrm{LiCoO}_{2}$ ratio $3: 1$, time $30 \mathrm{~min}$, and a solid/liquid ratio $16: 1(\mathrm{~g} / \mathrm{L})$, respectively. Moreover, PVC was completely dechlorinated at temperatures above $350^{\circ} \mathrm{C}$ without any release of toxic chlorinated organic compounds. Assessment on economical and environmental impacts revealed that the PVC and $\mathrm{LiCoO}_{2}$ subcritical co-treatment process had significant technical, economic and environmental benefits over the traditional hydrometallurgy and pyrometallurgy processes. This innovative co-treatment process is efficient, environmentally friendly and adequate for Co and Li recovery from spent LIBs and simultaneous dechlorination of PVC in subcritical water.
\end{abstract}

(C) 2016 Elsevier B.V. All rights reserved.

\section{Introduction}

Spent lithium-ion batteries (LIBs) contain large quantities of valuable metals such as cobalt (Co) and lithium ( $\mathrm{Li}$ ) and thus are an attractive secondary mineral resource [1-3]. Interest in recycling Co and Li from spent LIBs has recently increased for environmental and economic purposes [4-7]. Hydrometallurgy is preferred over pyrometallurgy for metal recovery from spent LIBs due to its low dust generation, simple working conditions, low energy consump-

\footnotetext{
* Corresponding author.

E-mail address: fszhang@rcees.ac.cn (F.-S. Zhang).
}

tion, and high recovery rate [8]. However, acids used during the hydrometallurgical process pose serious threats to human health and to the environment. Organic acids provide a possible environmentally friendly alternative for the recovery of Co and Li from spent LIBs [9-11]. These mild reactants give satisfactory results, but consume large quantities of chemical reagents, thus increasing recycling cost $[12,13]$. Therefore, if a suitable waste could be employed as the leaching agent for metal recovery, it would greatly reduce recycling costs by utilizing the strategy of waste treatment by waste.

Polyvinyl chloride (PVC) is widely used in the plastics industry due to its chemical stability and hardness, which can be tuned using chemical additives [14]. However, enormous PVC is disposed after 

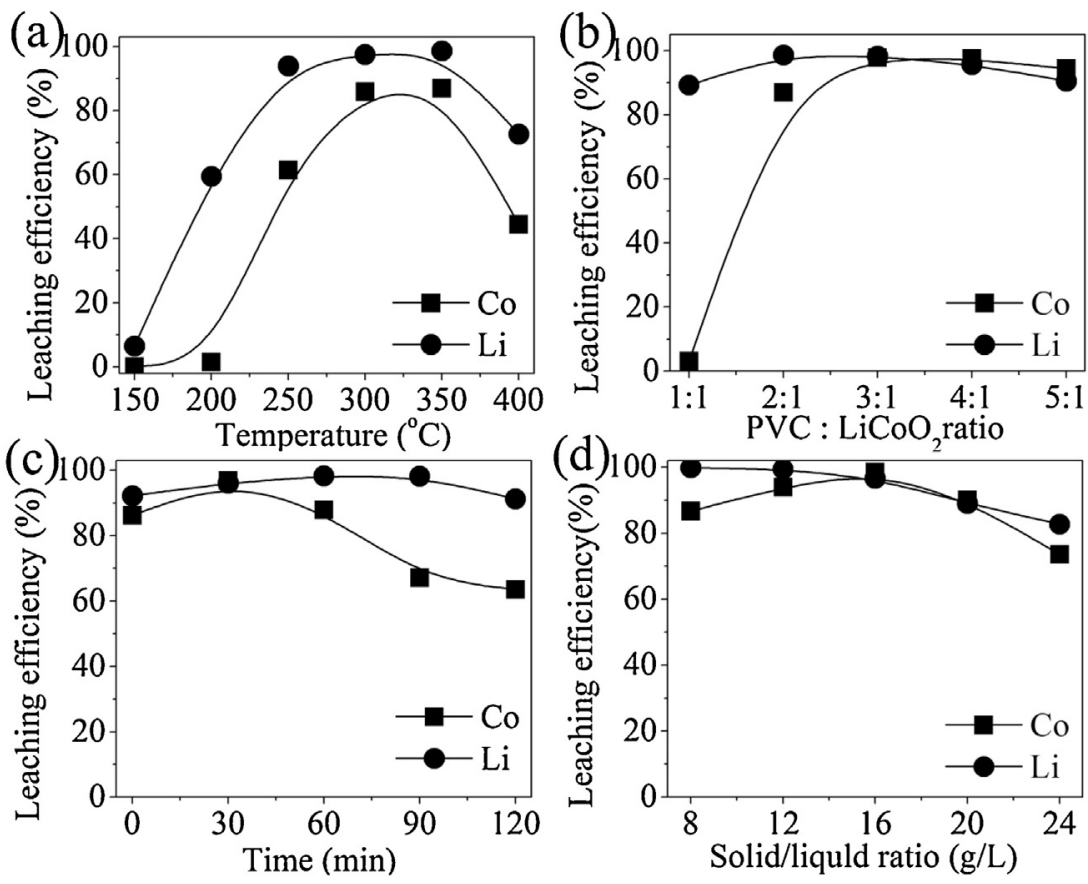

Fig. 1. Effects of (a) temperature (b) $\mathrm{PVC} / \mathrm{LiCoO}_{2}$ mass ratio (c) time (d) solid/liquid ratio on the leaching efficiencies of $\mathrm{Co}$ and $\mathrm{Li}$.

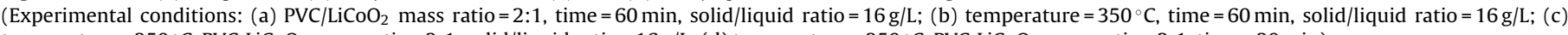
temperature $=350^{\circ} \mathrm{C}, \mathrm{PVC}: \mathrm{LiCoO}_{2}$ mass ratio $=3: 1$, solid/liquid ratio $=16 \mathrm{~g} / \mathrm{L} ;(\mathrm{d})$ temperature $=350{ }^{\circ} \mathrm{C}, \mathrm{PVC}_{\mathrm{LiCoO}} \mathrm{mass}$ ratio $=3: 1$, time $\left.=30 \mathrm{~min}\right)$.

the usage and is destined to be wasted. Proper disposal of this $\mathrm{Cl}$ containing polymer is a serious challenge since high-temperature incineration and thermal pyrolysis result in the formation of highly corrosive $\mathrm{HCl}$ and extremely toxic dioxins $[15,16]$. Therefore, there is a need to develop a reliable, safe and environmentally friendly way to treat these compounds that does not result in the release of chlorinated compounds into the environment.

In recent years, supercritical fluid (SCF) has been investigated as an environmentally friendly technology to solve environmental problems related with waste electrical and electronic equipment [17-19]. SCFs such as water [20], methanol [21] and acetone [22] have extraordinary properties (e.g. low viscosity, high mass transport coefficient, high diffusivity, and high solubility etc.) and are used as green solvents to decompose hazardous organic polymers. In SCF, hazardous organic polymers can be decomposed into small molecules, leading to environmental protection $[23,24]$. SCF is becoming an increasingly popular technique for the disposal of waste electronic equipment, however there is little research on its ability to recover metals from spent LIBs.

In this work, an effective and environmentally friendly process for the recovery of Co and Li from spent LIBs was developed. In this process, waste PVC was introduced into the subcriti$\mathrm{cal} /$ supercritical water system as an acid source to leach $\mathrm{Co}$ and $\mathrm{Li}$ from spent LIBs. Thus, dechlorination of waste PVC and the metal leaching could be achieved simultaneously. The effects of various parameters on leaching efficiencies of Co and Li were investigated and the mechanism underlying the co-treatment of the two wastes in subcritical water was discussed in detail.

\section{Experimental}

\subsection{Materials and reagents}

Spent LIBs were supplied by HuaXing Environmental Protection Company (Beijing, China). A commercially available PVC powder (Sinopharm Chemical Reagent Company of Beijing) was used in this study. The diameters of PVC particles were around 50-100 $\mu \mathrm{m}$.

\subsection{Dismantling, anode/cathode separation and $\mathrm{LiCoO}_{2}$ collection}

The spent LIBs were first discharged to discard any remaining capacity and then dismantled to remove the plastic and steel cases. During the dismantling, the anode and cathode materials were collected from the cells after the removal of plastic films. $N$-methyl2-pyrrolidone was used to effectively dissolve the polyvinylidene fluoride binder between the cathode materials and aluminum foil, while aluminum foil was recovered in its metallic form. The cathode materials containing $\mathrm{LiCoO}_{2}$ were washed and dried at $100^{\circ} \mathrm{C}$ for $1 \mathrm{~h}$ and then cooled to room temperature. After aqua regia digestion, Co and Li contents in cathode materials were measured using an inductively-coupled plasma optical emission spectrometer (ICPOES, Prodigy, Leeman, USA) and determined to be $51.8 \%$ and $6.5 \%$, respectively. The remaining weight in cathode materials is graphite.

\subsection{Metal leaching in subcritical/supercritical water}

The co-treating experiments in subcritical/supercritical water were carried out in $100 \mathrm{ml}$ high-pressure reactors, which were placed in an electric jacket to control the reaction temperature within a deviation of $\pm 2.0^{\circ} \mathrm{C}$. The cathode materials, PVC and deionized water were then introduced into the high-pressure reactors. The temperature varied from 150 to $400^{\circ} \mathrm{C}$. The reaction times and $\mathrm{PVC} / \mathrm{LiCoO}_{2}$ mass ratios were changed separately as required. After each reaction, the gas phase was passed through a $\mathrm{NaHCO}_{3}$ solution and the resulting liquid-solid mixture was separated by vacuum filtration.

\subsection{Analysis methods}

After co-treatment, Co and Li contents in solution were measured by ICP-OES. The metal leaching efficiency is determined as follows:

Metal leaching efficiency $(\%)=\mathrm{W}_{1} \times 100 / \mathrm{W}_{2}$ 
Table 1

Effect of mass ratio of PVC to $\mathrm{LiCoO}_{2}$ on solution $\mathrm{pH}$.

\begin{tabular}{|c|c|c|c|c|c|}
\hline $\mathrm{m}_{\mathrm{PVC}: \mathrm{LiCoO}}$ & $1: 1$ & $2: 1$ & $3: 1$ & $4: 1$ & $5: 1$ \\
\hline $\mathrm{PH}$ & 5.22 & 3.86 & 3.36 & 3.07 & 2.97 \\
\hline
\end{tabular}
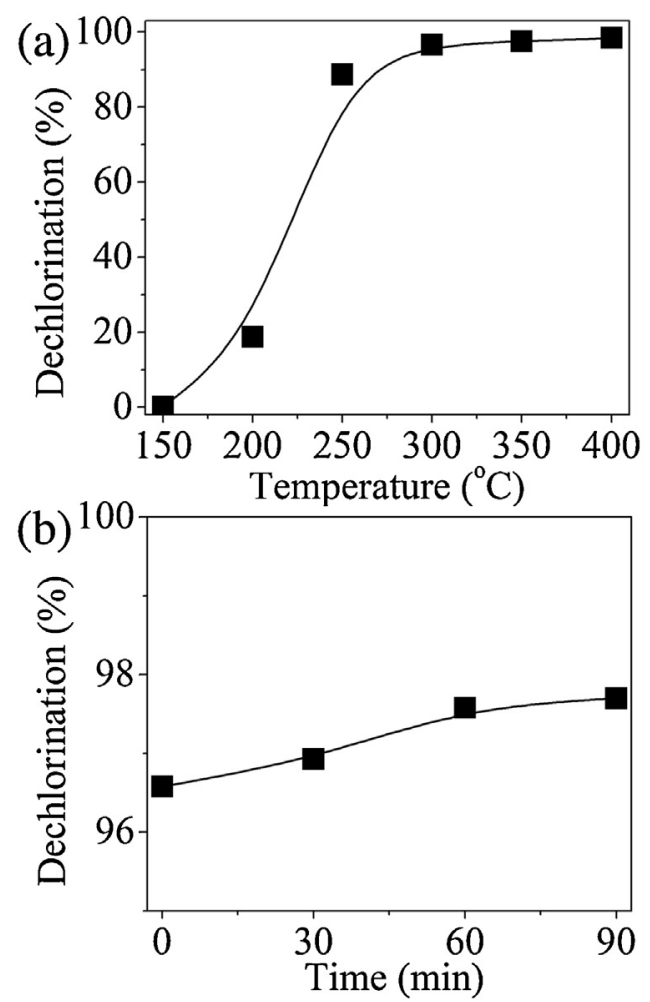

Fig. 2. Effects of (a) temperature and (b) time on PVC dechlorination.

(Experimental conditions: (a) $\mathrm{PVC} / \mathrm{LiCoO}_{2}$ mass ratio $=2: 1$, time $=60 \mathrm{~min}$, solid/liquid ratio $=16 \mathrm{~g} / \mathrm{L}$; (b) temperature $=350^{\circ} \mathrm{C}$, PVC: $\mathrm{LiCoO}_{2}$ mass ratio $=2: 1$, solid/liquid ratio $=16 \mathrm{~g} / \mathrm{L}$ ).

where $\mathrm{W}_{1}$ is the leached metal content and $\mathrm{W}_{2}$ is the initial metal content in the $\mathrm{LiCoO}_{2}$.

Chlorine contents in PVC and residue were analyzed by oxygen combustion bomb-ion chromatography (IC). Organic products after co-treatment were analyzed on a gas chromatography mass spectrometry system (GC/MS, Agilent 7890A/5975C, Agilent Technologies, USA) using hexane as an extraction agent. Solid products were characterized on a Bruker D8 X-ray powder diffractometer (XRD) under $50 \mathrm{kV}, 100 \mathrm{~mA}$ and $\mathrm{Cu} \mathrm{K} \alpha$ radiation $(\mathrm{k}=1.5418 \AA$ ). The morphological properties of the products were examined using a scanning electron microscopy and energy disperse X-ray system (SEM-EDX, S-3000 N, Hitachi, Japan).

\section{Results and discussion}

\subsection{Metal leaching}

\subsubsection{Effect of temperature}

$\mathrm{LiCoO}_{2}$ powder with PVC was treated by subcritical/supercritical water from 150 to $400^{\circ} \mathrm{C}$ to test the recovery of Co and Li from spent LIBs. As shown in Fig. 1a, the leaching efficiencies of Co and Li were negligible at co-treatment temperatures below $200^{\circ} \mathrm{C}$ due to inefficient PVC dechlorination below $200^{\circ} \mathrm{C}$. As the temperature rose, the leaching efficiencies of Co and Li increased significantly up to $61.4 \%$ and $93.9 \%$, respectively, at $250^{\circ} \mathrm{C}$. This phenomenon can be explained by the release of $\mathrm{Cl}$ in PVC by dehydrochlorination and its subsequent dissolution in water to form $\mathrm{HCl}$ [25]. Co and $\mathrm{Li}$ in
$\mathrm{LiCoO}_{2}$ can react with $\mathrm{HCl}$ to form stable $\mathrm{CoCl}_{2}$ and $\mathrm{LiCl}$ compounds, respectively. At $350^{\circ} \mathrm{C}$, the $\mathrm{Co}$ and Li leaching efficiencies further increased, which could be attributed to the complete dechlorination of PVC. The metal leaching efficiencies were also maximized. About $86.9 \%$ of $\mathrm{Co}$ and $98.6 \%$ of $\mathrm{Li}$ were leached at $350^{\circ} \mathrm{C}$. Any further rises in temperature did not improve the Co leaching efficiency. Conversely, $\mathrm{CoCl}_{2}$ became unstable in the supercritical water system at high temperatures and pressures. At $400^{\circ} \mathrm{C}$, the leaching efficiencies of $\mathrm{Co}$ and $\mathrm{Li}$ both decreased. The supercritical point of water was $374.2^{\circ} \mathrm{C}, 22.1 \mathrm{MPa}$, and the physicochemical properties of supercritical water were significantly different from that of subcritical water. When the reaction temperature was $350^{\circ} \mathrm{C}$, the physicochemical properties of subcritical water (e.g., density, ion product and dielectric constant) approached normal water, with relatively mild conditions in the system. When the reaction temperature was $400^{\circ} \mathrm{C}$, a large number of $\mathrm{H}^{+}$and $\mathrm{OH}^{-}$could be produced, accelerating the hydrolysis of $\mathrm{LiCl}$ and $\mathrm{CoCl}_{2}$ [26]. The following reactions could occur:

$\mathrm{LiCl}+\mathrm{H}^{+}+\mathrm{OH}^{-} \leftrightarrow \mathrm{LiOH}+\mathrm{HCl}$

$\mathrm{CoCl}_{2}+2 \mathrm{H}^{+}+2 \mathrm{OH}^{-} \leftrightarrow \mathrm{Co}(\mathrm{OH})_{2}+2 \mathrm{HCl}$

When the temperature reaches $400^{\circ} \mathrm{C}$, $\mathrm{Li}$ and Co have been leached from $\mathrm{LiCoO}_{2}$, but the contents detected in the solution decrease compared to that at $350^{\circ} \mathrm{C}$. Therefore, the optimal reaction temperature for $\mathrm{Co}$ and $\mathrm{Li}$ leaching is $350^{\circ} \mathrm{C}$.

\subsubsection{Effect of the $\mathrm{PVC} / \mathrm{LiCOO}_{2}$ mass ratio}

During the co-treatment of PVC and $\mathrm{LiCoO}_{2}$, the $\mathrm{PVC} / \mathrm{LiCoO}_{2}$ mass ratio plays a critical role in the efficiencies of metal leaching. As shown in Fig. 1b, the Co content in the resulting solution is negligible because of the low $\mathrm{HCl}$ content in solution. In addition, $\mathrm{Li}$ is efficiently leached from $\mathrm{LiCoO}_{2}$ at a $\mathrm{PVC} / \mathrm{LiCoO}_{2}$ ratio of $1: 1$. One explanation for this observation is that the small atomic radius, strong polarizability and high activity of $\mathrm{Li}$ in the $\mathrm{LiCoO}_{2}$ crystals promotes its initial reaction with $\mathrm{Cl}$ to form $\mathrm{LiCl}$, while the less active Co was not involved in the solution phase. The leaching efficiencies of $\mathrm{Co}$ and $\mathrm{Li}$ were improved at a mass ratio of 2:1 due to sufficient generation of $\mathrm{HCl}$ from the dechlorination of PVC. Furthermore, nearly $97.8 \%$ of $\mathrm{Co}$ and $98.3 \%$ of $\mathrm{Li}$ were leached into the subcritical water when the $\mathrm{PVC}-\mathrm{LiCoO}_{2}$ ratio was $3: 1$ after reacting at $350{ }^{\circ} \mathrm{C}$ for $60 \mathrm{~min}$. In this case, any further increase in the $\mathrm{PVC} / \mathrm{LiCoO}_{2}$ ratio did not improve the leaching efficiency of Co or $\mathrm{Li}$. We can therefore infer that increasing the PVC mass ratio in the mixture is conducive for the generation of excess $\mathrm{HCl}$, which promotes the leaching of Li and Co metals into the subcritical water system. This conclusion was also confirmed by the changing of the $\mathrm{pH}$ of system after co-treatment at different mass ratios. As shown in Table 1, the pH of the system decreased from 5.22 to 2.97 as the $\mathrm{PVC} / \mathrm{LiCoO}_{2}$ ratio increased from $1: 1$ to $5: 1$. Therefore, a ratio of $3: 1$ was suitable for the leaching of Co and Li.

\subsubsection{Effect of time}

The effect of reaction time shown in Fig. 1c demonstrates that, at the start of the reaction at $350^{\circ} \mathrm{C}$, over $86.2 \% \mathrm{Co}$ and $92.1 \% \mathrm{Li}$ were leached, indicating that subcritical co-treatment of PVC and $\mathrm{LiCoO}_{2}$ is an efficient process for leaching of $\mathrm{Co}$ and $\mathrm{Li}$ from $\mathrm{LiCoO}_{2}$. Even during the process of raising the temperature, along with the PVC dechlorination, the majority of the metals were already leached from the $\mathrm{LiCoO}_{2}$ powder. The leaching efficiencies of Co 


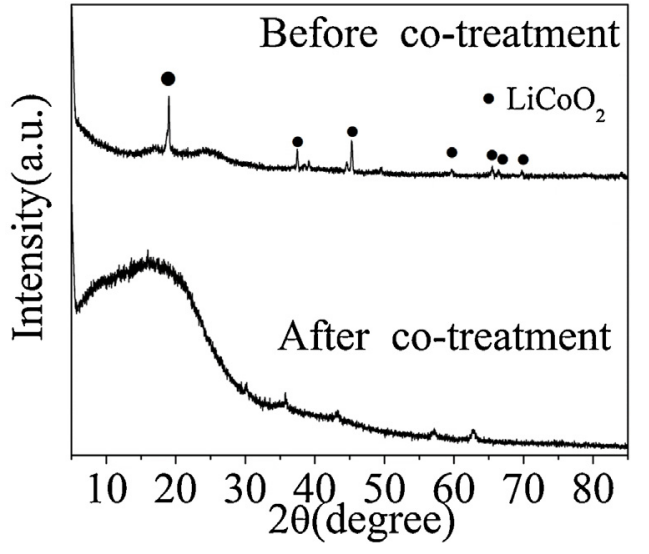

Fig. 3. XRD patterns of solid products before and after co-treatment.

and $\mathrm{Li}$ increased with longer reaction times. After $30 \mathrm{~min}$, the Co and Li leaching efficiencies were improved to $96.8 \%$ and $96.1 \%$, respectively. However, after a reaction time of $60 \mathrm{~min}$, the leaching efficiencies of Co and Li both decreased significantly. With the extension of reaction time, etching reaction may occur slowly between the metallic inwall of hydrothermal reactor and $\mathrm{Li}^{+} / \mathrm{Co}^{2+}$ in the solution. Therefore, the optimum time for Co and Li leaching is $30 \mathrm{~min}$.

\subsubsection{Effect of solid/liquid ratio}

As the solid/liquid ratio increased, the Co leaching efficiency was improved (Fig. 1d), while the Li leaching efficiency was reduced slightly. The leaching efficiencies of both Co and Li peaked at a solid/liquid ratio of $16: 1 \mathrm{~g} / \mathrm{L}$. Therefore, the most suitable solid/liquid ratio for both Co and Li leaching was $16: 1 \mathrm{~g} / \mathrm{L}$. Based on the experimental results above, the optimum co-treatment conditions for Co and Li leaching were determined to be: temperature of $350^{\circ} \mathrm{C}, \mathrm{PVC} / \mathrm{LiCoO}_{2}$ ratio of $3: 1$, time of $30 \mathrm{~min}$ and solid/liquid ratio of $16: 1 \mathrm{~g} / \mathrm{L}$. Under these conditions, the maximum leaching efficiency is $98.4 \%$ Co and $96.6 \% \mathrm{Li}$.

\subsection{Dechlorination behavior of PVC in subcritical/supercritical water}

\subsubsection{Effect of temperature}

Temperature can dramatically affect dechlorination of PVC in subcritical/supercritical water oxidation. High reaction temperatures provide enough energy to break down the chemical bonds of PVC and improve the dechlorination efficiency [27]. Fig. 2a illustrates the effects of temperature on the dechlorination behavior of PVC in subcritical/supercritical water oxidation. PVC dechlorination was negligible at lower temperatures below $200^{\circ} \mathrm{C}$. Dechlorination was improved at higher temperatures and exceeded 96.6\% above $300{ }^{\circ} \mathrm{C}$. The percentage of dechlorinated PVC increases with temperature, gradually approaching a saturated level at $97.6 \%$ after a $1 \mathrm{~h}$ treatment above $350^{\circ} \mathrm{C}$. At $350^{\circ} \mathrm{C}$, all of the $\mathrm{HCl}$ released from PVC is captured by $\mathrm{LiCoO}_{2}$.

\subsubsection{Effect of time}

Fig. 2b illustrates the effects of time on PVC dechlorination at $350^{\circ} \mathrm{C}$. The initial extent of PVC dechlorination measured was $96.5 \%$, and then stabilized around $97.0 \%$ for all residence time durations studied. This result indicated that PVC dechlorination in subcritical water proceeded continuously as the temperature increased. When the initial temperature was reached, the majority of $\mathrm{Cl}$ in PVC was already released into the subcritical water system. The dechlorination of PVC was not dependent on the residence time after $30 \mathrm{~min}$. Therefore, we infer that $30 \mathrm{~min}$ is sufficient enough time for the release of all $\mathrm{Cl}$ from PVC into the subcritical water at $350^{\circ} \mathrm{C}$. These findings are consistent with the observed leaching trends of $\mathrm{Co}$ and $\mathrm{Li}$ in the subcritical/supercritical water system,
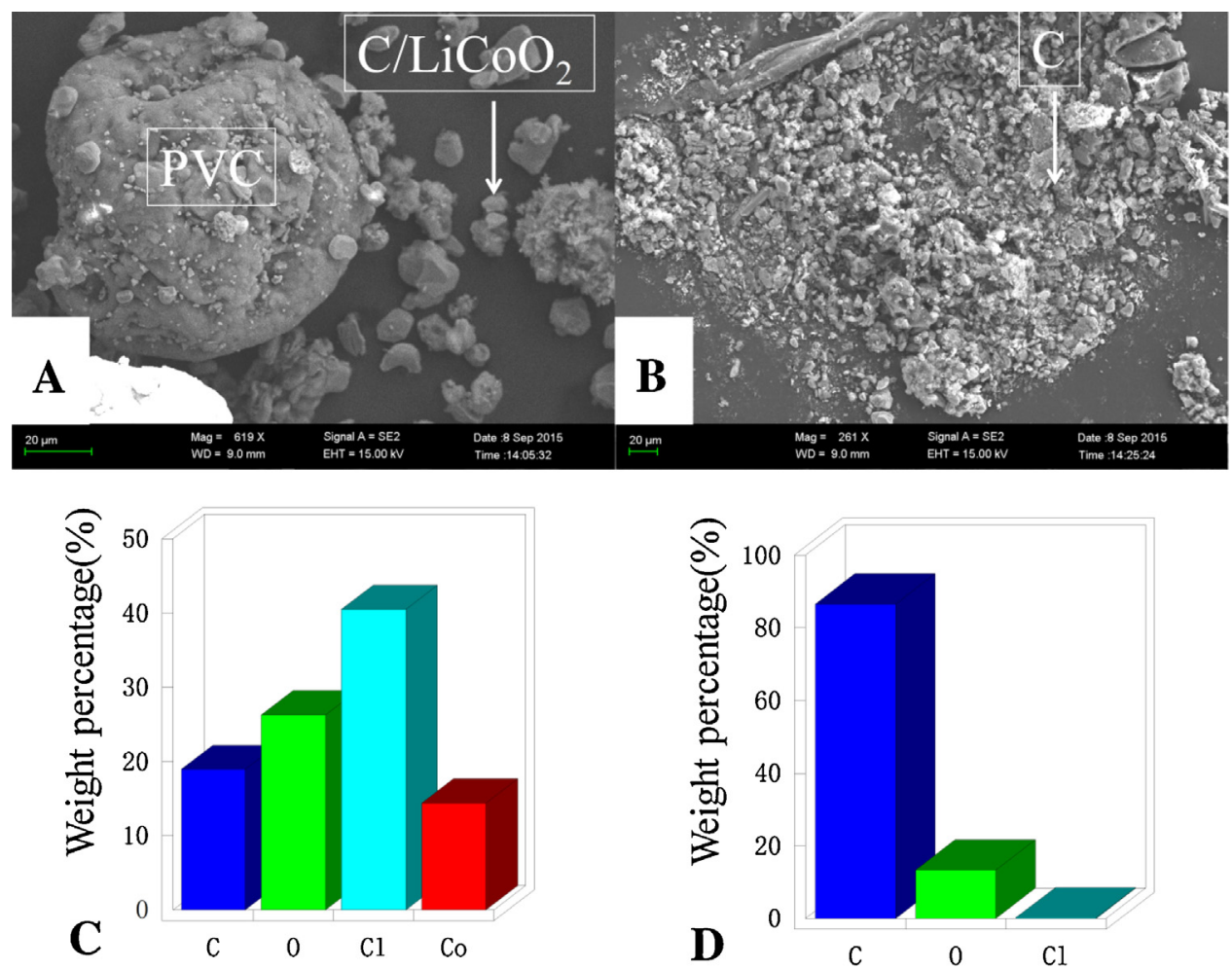

Fig. 4. SEM-EDX analysis of $\mathrm{LiCoO}_{2}$ and PVC. SEM images (a) before and (b) after co-treatment; EDX analysis (c) before and (d) after co-treatment. 
Table 2

GC-MS analysis of oil products.

\begin{tabular}{|c|c|c|c|}
\hline Ret. time (min) & Components & Structure & Areas (\%) \\
\hline 7.849 & $\mathrm{C}_{7} \mathrm{H}_{6} \mathrm{O}$ & & $66.43 \%$ \\
\hline 10.483 & $\mathrm{C}_{13} \mathrm{H}_{18} \mathrm{O}$ & & $11.54 \%$ \\
\hline 14.399 & $\mathrm{C}_{14} \mathrm{H}_{22} \mathrm{O}_{2}$ & & $2.68 \%$ \\
\hline 15.764 & $\mathrm{C}_{16} \mathrm{H}_{12} \mathrm{O}_{3}$ & & 19.44 \\
\hline
\end{tabular}

Table 3

Comparison of economic evaluations and environmental impacts on different methods.

\begin{tabular}{llll}
\hline Method & Pyrometallurgy & Hydrometallurgy & Co-treatment \\
\hline Spent LIBs cost $(\$ / \mathrm{kg})$ & 10 & 10 & 10 \\
Reagent cost $(\$ / \mathrm{kg})$ & 0 & $\mathrm{H}_{2} \mathrm{O}_{2}$ and acid & 0 \\
Metals recovery rate $(\%)$ & $<95 \%$ & $<95 \%$ & $<95 \%$ \\
Equipment cost $(\mathrm{K} \$)$ & 600 & - & 100 \\
Power $(\mathrm{kW})$ & 4 & None & 2 \\
Temperature $\left({ }^{\circ} \mathrm{C}\right)$ & 1000 & $60-80$ & 350 \\
Extraneous earnings & None & None & Benzene derivative \\
Environmental effects & Waste gas & Waste water & None \\
\hline
\end{tabular}

suggesting that the dechlorination of PVC is synchronized with the leaching of $\mathrm{Co}$ and $\mathrm{Li}$.

\subsubsection{Effect of PVC particle size}

Fig. S1 shows the comparison picture of PVC with different particle sizes before and after co-treatment in subcritical water. PVC with larger particle size $(1000-2000 \mu \mathrm{m})$ maintains original shape after co-treatment in subcritical water. However, the granule interior have been carbonized-black and round particles can be smashed by extrusion. Fig. S2 shows dechlorination efficiency of PVC with different particle sizes and metal leaching efficiency in subcritical water. With the increase of PVC particle size, dechlorination and metal leaching efficiency slightly decrease. There is a large contact area between PVC (with small particle size $\approx 100 \mu \mathrm{m}$ ) and water. $\mathrm{HCl}$ generated by hydrothermal decomposition can be quickly spread and dissolved in subcritical water. In contrast, there is a small contact area between PVC (with large particle size $\approx 1000$ and $2000 \mu \mathrm{m}$ ) and water. Dechlorination occurs from the outside to inside, leading to inadequate PVC degradation. The limited dechlorination cannot provide sufficient $\mathrm{H}^{+}$and $\mathrm{Cl}^{-}$for the leaching of $\mathrm{Li}$ and Co. Therefore, we infer that PVC with the smaller particle size will lead to more full degradation reaction in subcritical water, with higher metal leaching efficiency.

In the conventional PVC chemical treatment, pyrolysis is easy to produce toxic dioxins as well as coke and pyrolysis oil adhering to the pipe inner wall (which is difficult to be cleaned) [14]. Furthermore, dechlorination reagents such as $\mathrm{CaO}$ and $\mathrm{La}_{2} \mathrm{O}_{3}$ are needed to dispose waste PVC by mechanochemical method. It is difficult to separate dechlorination reagents from degradation product $[28,29]$. Using subcritical water to dispose waste PVC has the following advantages-fast dechlorination speed, no additional additives, without volatile organics containing chlorine, and the recycling of $\mathrm{HCl}$ and chemical products. Therefore, it has significant

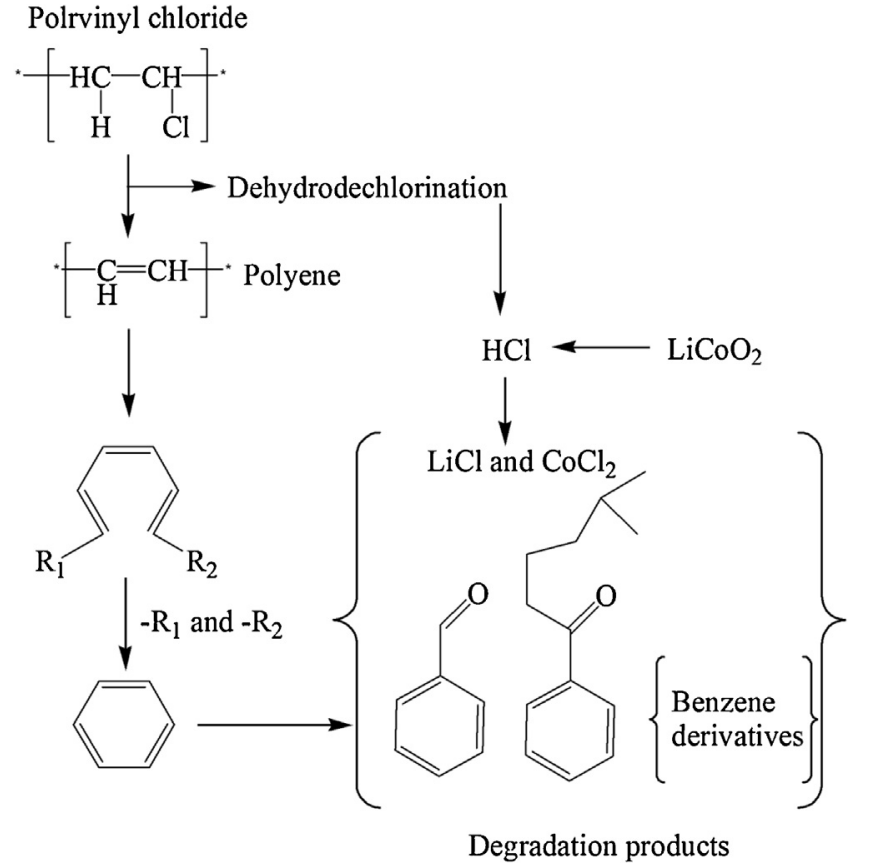

Fig. 5. Interaction route of $\mathrm{PVC}$ and $\mathrm{LiCoO}_{2}$ during co-treatment in subcritical water.

technical advantages by using subcritical water to dispose waste PVC compared with other conventional chemical methods.

\subsection{Product characterization}

\subsubsection{XRD, SEM-EDX analysis of solid products}

Fig. 3 shows XRD spectra of the $\mathrm{LiCoO}_{2}$ and PVC products before and after co-treatment. The XRD patterns of the solid products before co-treatment clearly show the crystalline $\mathrm{LiCoO}_{2}$ phase (Fig. 3). The XRD patterns of the solid products after co-treatment at $350^{\circ} \mathrm{C}$ show the appearance of an amorphous diffraction peak at $10^{\circ}-30^{\circ}$ due to PVC dechlorination at high temperatures and the complete disappearance of the diffraction peak of the $\mathrm{LiCoO}_{2}$ phase due to dissolution of the metal. Amorphous peaks can therefore be attributed to the residue of graphite from cathode material.

In addition, the SEM image of solid products before co-treatment shows regular round particles, with graphite and $\mathrm{LiCoO}_{2}$ attached on the surface (Fig. S3 and Fig. 4a). When dechlorination occurred, the PVC was degraded into $\mathrm{HCl}$ and. Only the graphite from $\mathrm{LiCoO}_{2}$ can be detected in the microscopic view (Fig. 4b). EDX shows that the $\mathrm{Cl}$ content in solid products after co-treatment was reduced to almost zero (Fig. 4c and d). Based on the statistical analyses, quantitative analyses, XRD, and SEM, it can be generally concluded that subcritical water oxidation is able to synchronize the $\mathrm{Co} / \mathrm{Li}$ leaching from $\mathrm{LiCoO}_{2}$ and the $\mathrm{Cl}$ removal from PVC.

\subsubsection{GC-MS analysis of oil products}

The main organic products formed after PVC dechlorination in subcritical water are benzene derivatives (Table 2). Based on the identified organic products, the mechanism of PVC and $\mathrm{LiCoO}_{2} \mathrm{CO}-$ treatment in subcritical water was investigated (Fig. 5). Takeshita et al. [30] reported that PVC was dehydrochlorinated by the zipper mechanism, in which the loss of $\mathrm{HCl}$ from a given two-carbon segment is facilitated by dehydrochlorination of an adjacent monomer unit. In the subcritical co-treatment process, $\mathrm{HCl}$ dissolved in water to become hydrochloric acid, inducing the rapid leaching of metals from the $\mathrm{LiCoO}_{2}$ crystals. The resulting polyenes underwent chain rupture to form small-molecule compounds. In addition, these polyenes undergo intermolecular and intramolecular Diels- 


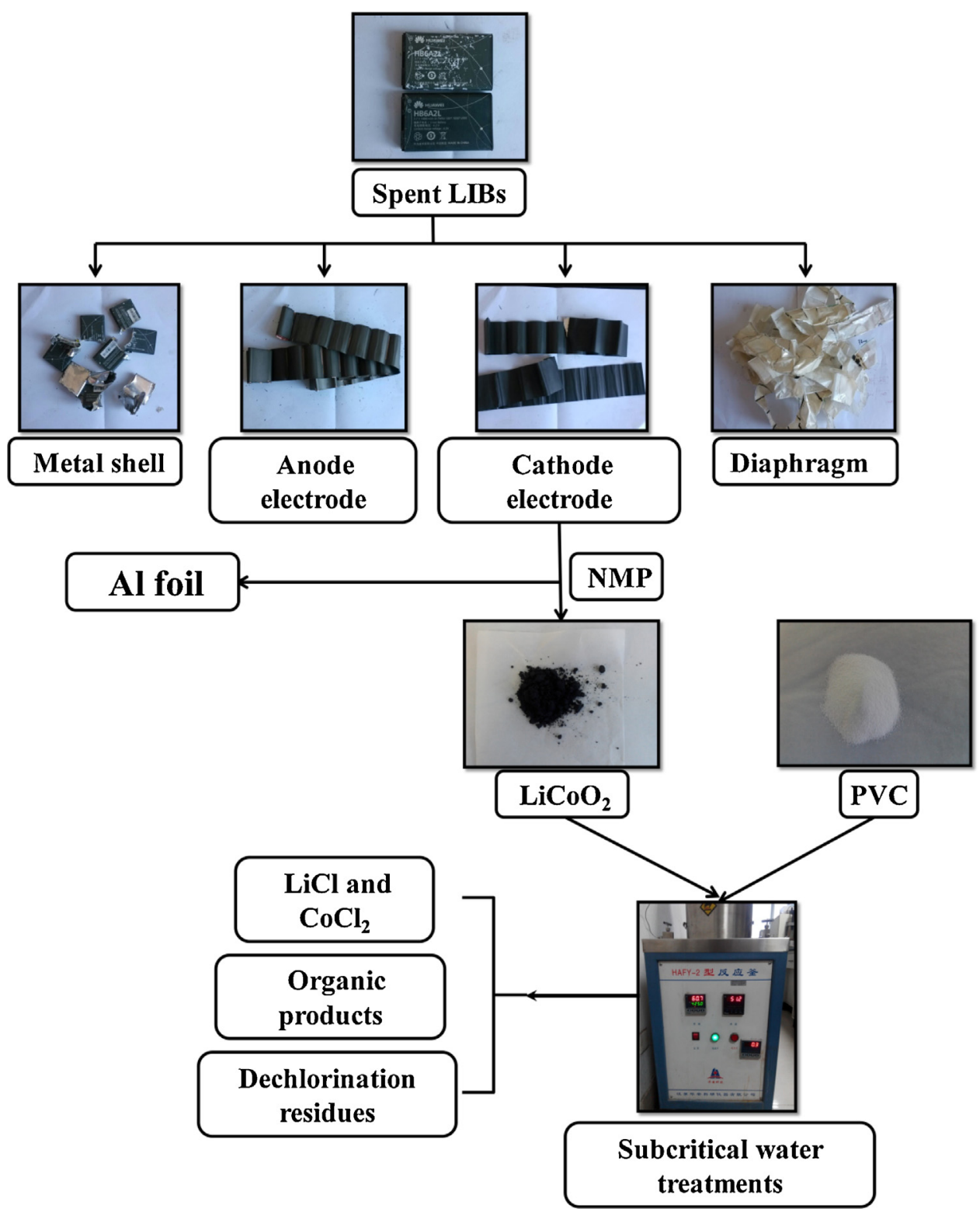

Fig. 6. Schematic diagram of the proposed co-treatment process.

Alder reactions to form benzene rings. The cyclization, hydrolysis, pyrolysis and oxidation interactions in the subcritical water result in further formation of benzene derivatives. Based on the above results, the following reaction equation can be given:

$\mathrm{LiCoO}_{2}+3\left[-\mathrm{CH}_{2} \mathrm{CHCl}-\right]_{\mathrm{n}} \rightarrow \mathrm{LiCl}+\mathrm{CoCl}_{2}+\mathrm{C}_{x} \mathrm{H}_{y} \mathrm{O}_{z}$

Therefore, the proposed co-treatment process is safe and environmentally friendly, and avoids the release of toxic chlorinated organic compounds.

\subsection{Economic feasibility and environmental impact evaluation}

Fig. 6 shows the flow chart describing steps towards recovering metals from spent LIBs via the co-treatment process in subcritical water. Based on the flow chart and product analysis discussed above, we evaluated the economic feasibility and environmental impacts of the laboratory-scale PVC and $\mathrm{LiCoO}_{2}$ subcritical water co-treatment process and compared it with the traditional hydrometallurgy and pyrometallurgy processes. Table 3 shows the process flows, recovery effects and operation energy consump- tions of the three processes. The subcritical co-treatment process has essentially the same lithium battery dismantling process and metal recovery efficiency as the hydrometallurgy and pyrometallurgy processes. In comparison, hydrometallurgy requires the use of an acid source, such as strong acids $\left(\mathrm{HNO}_{3}, \mathrm{H}_{2} \mathrm{SO}_{4}\right.$ and $\left.\mathrm{HCl}\right)$ or inorganic acids [9,10,31]. In addition, in order to accelerate the leaching of $\mathrm{Co}^{3+}$ from $\mathrm{LiCoO}_{2}$, hydrometallurgy requires the addition of a reductant (e.g. $\mathrm{H}_{2} \mathrm{O}_{2}$ ) to convert $\mathrm{Co}^{3+}$ to $\mathrm{Co}^{2+}[9,10,32]$. Moreover, the pyrometallurgy equipment is highly expensive, with reaction temperatures generally above $700-1000^{\circ} \mathrm{C}$, resulting in a large consumption of energy [6,33]. In comparison, the subcritical co-treatment did not require other reagents other than the waste PVC, and used a temperature of only $350^{\circ} \mathrm{C}$. Furthermore, the waste PVC has the extra benefit of being simultaneously converted to chemical raw materials. We believe that this work has the potential commercial applications. Further commercial production needs to consider many factors such as equipment, work space and separation costs. The commercial cost of this work is mainly determined by the price of hydrothermal equipment (100 $\mathrm{K} \$$ ) and the power consumption $(0.07735 \$$ for each test in our city). 
Comparison with environmental impacts of different LIB recovery processes revealed that the subcritical water co-treatment process did not have any environmental impacts. After the reaction, the $\mathrm{Cl}$ present in PVC bound with the metals to form nontoxic inorganic chlorine, avoiding the generation of any environmentally destructive organic chlorine compounds. The resulting metal chlorides can be separated and recovered via subsequent precipitation, allowing the waste liquids to be converted into highly pure hydrosolvents, which were recycled into the high-pressure reactor [34]. In comparison, the pyrometallurgy process generates toxic waste gas and thus causes secondary pollution to the environment. Therefore, the PVC and $\mathrm{LiCoO}_{2}$ subcritical co-treatment process has significant technical, economic and environmental benefits over the traditional recovery processes, and thus has wide development prospects in metal recovery from spent LIBs.

\section{Conclusions}

This work innovatively performed the co-treatment of cathode material $\left(\mathrm{C} / \mathrm{LiCoO}_{2}\right)$ from spent LIBs and PVC in subcritical water. Using hydrochloric acid produced by dechlorination of PVC in subcritical water as acid source, $\mathrm{Li}$ and Co were leached from $\mathrm{LiCoO}_{2}$. Characterizations of XRD, SEM-EDX and GC-MS showed the organochlorine in PVC has been converted into inorganic $\mathrm{Cl}$ ligand of Li and Co after co-treatment in subcritical water. PVC was synchronously converted into useful chemical materials, without organics containing $\mathrm{Cl}$ in the co-treatment process. The proposed process provides a new recycling method and technology for harmless and resourceful treatment of spent LIBs and waste PVC.

\section{Acknowledgments}

This research was financially supported by the National Natural Science Foundation of China (21477151, 51278485), the Strategic Priority Research Program of the Chinese Academy of Sciences (XDB05050200) and the Science Promotion Program of Research Center for Eco-Environmental Sciences, CAS (YSW2013B05).

\section{Appendix A. Supplementary data}

Supplementary data associated with this article can be found, in the online version, at http://dx.doi.org/10.1016/j.jhazmat.2016.04. 080.

\section{References}

[1] J. Xu, H. Thomas, R.W. Francis, K.R. Lum, J. Wang, B. Liang, A review of processes and technologies for the recycling of lithium-ion secondary batteries, J. Power Sources 177 (2008) 512-527.

[2] Q. Tan, J. Li, Recycling metals from wastes: a novel application of mechanochemistry, Environ. Sci. Technol. (2015).

[3] X. Zeng, R. Gong, W.-Q. Chen, J. Li, Uncovering the recycling potential of 'New'WEEE in China, Environ. Sci. Technol. (2015).

[4] X. Zeng, J. Li, N. Singh, Recycling of spent lithium-ion battery: a critical review, Crit. Rev. Environ. Sci. Technol. 44 (2014) 1129-1165.

[5] X. Zeng, J. Li, L. Liu, Solving spent lithium-ion battery problems in China: opportunities and challenges, Renew. Sustain. Energy Rev. 52 (2015) 1759-1767.

[6] J. Li, G. Wang, Z. Xu, Environmentally-friendly oxygen-free roasting/wet magnetic separation technology for in situ recycling cobalt, lithium carbonate and graphite from spent $\mathrm{LiCOO}_{2}$ /graphite lithium batteries, J. Hazard. Mater. 302 (2016) 97-104.
[7] D.H.P. Kang, M. Chen, O.A. Ogunseitan, Potential environmental and human health impacts of rechargeable lithium batteries in electronic waste, Environ. Sci. Technol. 47 (2013) 5495-5503.

[8] X. Zeng, J. Li, B. Shen, Novel approach to recover cobalt and lithium from spent lithium-ion battery using oxalic acid, J. Hazard. Mater. 295 (2015) 112-118.

[9] L. Li, J.B. Dunn, X.X. Zhang, L. Gaines, R.J. Chen, F. Wu, K. Amine, Recovery of metals from spent lithium-ion batteries with organic acids as leaching reagents and environmental assessment, J. Power Sources 233 (2013) $180-189$

[10] L. Li, W. Qu, X. Zhang, J. Lu, R. Chen, F. Wu, K. Amine, Succinic acid-based leaching system: a sustainable process for recovery of valuable metals from spent Li-ion batteries, J. Power Sources 282 (2015) 544-551.

[11] L. Li, J. Ge, F. Wu, R. Chen, S. Chen, B. Wu, Recovery of cobalt and lithium from spent lithium ion batteries using organic citric acid as leachant, J. Hazard. Mater. 176 (2010) 288-293.

[12] M. Joulié, R. Laucournet, E. Billy, Hydrometallurgical process for the recovery of high value metals from spent lithium nickel cobalt aluminum oxide based lithium-ion batteries, J. Power Sources 247 (2014) 551-555.

[13] G.P. Nayaka, J. Manjanna, K.V. Pai, R. Vadavi, S.J. Keny, V.S. Tripathi, Recovery of valuable metal ions from the spent lithium-ion battery using aqueous mixture of mild organic acids as alternative to mineral acids, Hydrometallurgy 151 (2015) 73-77.

[14] J. Yu, L. Sun, C. Ma, Y. Qiao, H. Yao, Thermal degradation of PVC: a review, Waste Manage. 48 (2016) 300-314.

[15] C. Vogel, R.M. Exner, C. Adam, Heavy metal removal from sewage sludge ash by thermochemical treatment with polyvinylchloride, Environ. Sci. Technol. 47 (2012) 563-567.

[16] M. Sadat-Shojai, G.-R. Bakhshandeh, Recycling of PVC wastes, Polym. Degrad. Stab. 96 (2011) 404-415.

[17] R. Wang, Y. Chen, Z. Xu, Recycling acetic acid from polarizing film of waste liquid crystal display panels by sub/supercritical water treatments, Environ. Sci. Technol. (2015).

[18] S.M. Al-Salem, P. Lettieri, J. Baeyens, Recycling and recovery routes of plastic solid waste (PSW): a review, Waste Manage. 29 (2009) 2625-2643.

[19] L. Qian, S. Wang, D. Xu, Y. Guo, X. Tang, L. Wang, Treatment of municipal sewage sludge in supercritical water: a review, Water Res. 89 (2016) 118-131.

[20] M. Xing, F.-S. Zhang, Degradation of brominated epoxy resin and metal recovery from waste printed circuit boards through batch sub/supercritical water treatments, Chem. Eng. J. 219 (2013) 131-136.

[21] F.-R. Xiu, F.-S. Zhang, Materials recovery from waste printed circuit boards by supercritical methanol, J. Hazard. Mater. 178 (2010) 628-634.

[22] Y. Wang, F.-S. Zhang, Degradation of brominated flame retardant in computer housing plastic by supercritical fluids, J. Hazard. Mater. 205 (2012) 156-163.

[23] P.E. Savage, Organic chemical reactions in supercritical water, Chem. Rev. 99 (1999) 603-622.

[24] K. Li, Z. Xu, Application of supercritical water to decompose brominated epoxy resin and environmental friendly recovery of metals from waste memory module, Environ. Sci. Technol. 49 (2015) 1761-1767.

[25] J. Poerschmann, B. Weiner, S. Woszidlo, R. Koehler, F.D. Kopinke, Hydrothermal carbonization of poly(vinyl chloride), Chemosphere 119 (2015) 682-689.

[26] D. Bröll, C. Kaul, A. Krämer, P. Krammer, T. Richter, M. Jung, H. Vogel, P. Zehner, Chemistry in supercritical water, Angew. Chem. Int. Ed. 38 (1999) 2998-3014

[27] G. Brunner, Near critical and supercritical water. Part I. Hydrolytic and hydrothermal processes, J. Supercrit. Fluids 47 (2009) 373-381.

[28] S. Saeki, J. Kano, F. Saito, K. Shimme, S. Masuda, T. Inoue, Effect of additives on dechlorination of PVC by mechanochemical treatment, J. Mater. Cycles Waste Manage. 3 (2001) 20-23.

[29] W. Tongamp, Q. Zhang, F. Saito, Mechanochemical decomposition of PVC by using $\mathrm{La}_{2} \mathrm{O}_{3}$ as additive, J. Hazard. Mater. 137 (2006) 1226-1230.

[30] Y. Takeshita, K. Kato, K. Takahashi, Y. Sato, S. Nishi, Basic study on treatment of waste polyvinyl chloride plastics by hydrothermal decomposition in subcritical and supercritical regions, J. Supercrit. Fluids 31 (2004) 185-193.

[31] J. Kang, G. Senanayake, J. Sohn, S.M. Shin, Recovery of cobalt sulfate from spent lithium ion batteries by reductive leaching and solvent extraction with Cyanex 272, Hydrometallurgy 100 (2010) 168-171.

[32] L. Li, L. Zhai, X. Zhang J. Lu, R. Chen, F. Wu, K. Amine, Recovery of valuable metals from spent lithium-ion batteries by ultrasonic-assisted leaching process, J. Power Sources 262 (2014) 380-385.

[33] L. Sun, K. Qiu, Vacuum pyrolysis and hydrometallurgical process for the recovery of valuable metals from spent lithium-ion batteries, J. Hazard. Mater. 194 (2011) 378-384.

[34] P. Zhang, T. Yokoyama, O. Itabashi, T.M. Suzuki, K. Inoue, Hydrometallurgical process for recovery of metal values from spent lithium-ion secondary batteries, Hydrometallurgy 47 (1998) 259-271. 